\title{
ATTITUDES TOWARDS ECT: A SURVEY OF POLISH MENTAL HEALTH PROFESSIONALS
}

\author{
Anna Antosik-Wójcińska ${ }^{1}$, Gabor Gazdag ${ }^{2,3}$, Lukasz Święcicki ${ }^{1}$, Beata Majtczak ${ }^{4}$, \\ Janusz Rybakowski ${ }^{5}$, Pawel Gosek ${ }^{6}$ \& Adam Wichniak ${ }^{7}$ \\ ${ }^{1}$ Second Department of Psychiatry, Institute of Psychiatry and Neurology, Warsaw, Poland \\ ${ }^{2}$ Centre for Psychiatry and Addiction Medicine, Jahn Ferenc South Pest Hospital, Budapest, Hungary \\ ${ }^{3}$ Department of Psychiatry and Psychotherapy, Semmelweis University, Budapest, Hungary \\ ${ }^{4}$ Sixth Department of Psychiatry, Hospital in Gostynin, Poland \\ ${ }^{5}$ Department of Adult Psychiatry, Poznan University of Medical Sciences, Poland \\ ${ }^{6}$ Forensic Psychiatry Clinic, Institute of Psychiatry and Neurology, Warsaw, Poland \\ ${ }^{7}$ Third Department of Psychiatry and Department of Clinical Neurophysiology, \\ Institute of Psychiatry and Neurology, Warsaw, Poland
}

received: 17.7.2017;

revised: 23.8.2018;

accepted: 9.10 .2018

\section{SUMMARY}

Background: Although the efficacy of electroconvulsive therapy (ECT) has been well established, the utilization rate of ECT has decreased in Poland in recent years. One of the main reasons could be the negative attitude towards ECT in the community and by mental health professionals. The aim of this study was to assess the knowledge about and attitudes toward ECT in Polish mental health professionals including psychiatrists and non-physicians: nurses, psychologists, social workers.

Subject and methods: Psychiatrists and other mental health professionals in two large Polish hospitals were approached to participate in the survey by completing a 28-item questionnaire. The specific hospitals have been selected due to the fact that they were located in the same province of Poland (Mazowsze), had similar catchment area and profile, provided similar mental health services with only one exception; one offered ECT while the other did not. Of the 185 questionnaires that had been distributed, 165 were completed yielding a response rate of $89.19 \%$. The study population consists of 85 psychiatrists and trainees and 80 nonphysicians.

Results: Psychiatrists did not differ from other mental health professionals with respect to the knowledge and attitudes toward ECT. However, there were significant differences in the attitude $(9.1 \pm 3.8$ vs $7.1 \pm 3.3 ; p<0.001)$ and knowledge $(5.9 \pm 3.8 v \mathrm{~s} 2.8 \pm 4.1$; $p<0.001)$ scores between those professionals, who have ever worked in a psychiatric ward where they could observe ECT sessions and those who have not had such an opportunity.

Conclusions: Frequent witnessing of ECT sessions seems to be the most effective educational intervention to change negative attitudes towards ECT.

Key words: electroconvulsive therapy - ACT - attitudes - mental health professionals - Poland

$$
* * * * *
$$

\section{INTRODUCTION}

Electroconvulsive therapy (ECT) was introduced in the therapeutic armamentarium of psychiatry in the 1930s. Before the era of modern psychopharmacology ECT was extensively used for a wide variety of psychiatric disorders (Krepela et al. 2019). Although the efficacy of electroconvulsive therapy has been well established particularly in depression and catatonia and it is included in most recent treatment guidelines (Grunze et al. 2009, 2010, Bauer at al. 2013, Hasan et al. 2012, 2015, Ellis et al. 2004, Royal Australian and New Zealand College of Psychiatrists Clinical Practice Guidelines Team for Bipolar Disorder, Australian and New Zealand clinical practice guidelines for the treatment of bipolar disorder 2004), its utilization rate has declined in some countries in the past decades (Leiknes et al. 2012, Palińska et al. 2008), while in some Eastern European countries ECT has been long under-utilized (Palińska et al. 2008). Causes identified to account for the low frequency of ECT use include negative attitudes towards and insufficient knowledge about the method in the professional community (Golenkov et al. 2010, Gazdag et al. 2004, 2011, 2009a,b, Chanpattana 1999, Finch et al. 1999). Negative attitude and misbelieves play an important role in the refusal of being treated with ECT from the lay public side (Janicak et al. 1985, Lauber et al. 2005). Beside psychological causes, financial reasons, lack of modern ECT machines and separate financing for the procedure as well as unavailability of anesthesiologist were also reported (Janicak et al. 1985, Lauber et al. 2005).

Historically the availability and use of ECT in Poland has been low mainly because of the community and mental health professionals' negative attitude (Palińska et al. 2008, Nasierowski 2002). Current indications for ECT have been restricted to clearly defined situations when rapid improvement is essential, such as life-threatening conditions particularly psychotic depression with suicidal ideation and catatonic stupor. Further indications are pharmacotherapy resistant depression or psychosis (Hese \& Zyss 2007, Zyss et al. 2017). 
To date, there has been no systematic evaluation of attitudes either in the general population or mental health professionals in Poland. The aim of this study was to survey attitudes towards and knowledge about ECT in Polish mental health professionals working in two Polish psychiatric hospitals.

\section{SUBJECTS AND METHODS}

\section{Participants}

Participants of the study were psychiatrists, nurses, psychologists, occupational therapists and social workers working in two large hospitals located in the same province of Poland (Mazowsze). Both hospitals were chosen because they differ in the availability of ECT services. At the Institute of Psychiatry and Neurology in Warsaw each year about 700 ECT procedures are performed, while at the Hospital in Gostynin ECT is not used at all. Altogether 185 subjects were invited to participate in the study.

\section{Attitude questionnaire}

A self-administered questionnaire (Appendix) comprising basic demographic data and 28 questions on knowledge and attitude towards ECT was given to all mental health professionals at Institute of Psychiatry and Neurology in Warsaw and two psychiatric wards at the hospital in Gostynin, one biologically oriented, acute psychiatric ward and one therapeutically oriented psychiatric rehabilitation ward. The questionnaire was a tailored version of a standard one used in attitude studies in other countries (Golenkov et al. 2010, Gazdag et al. 2004, 2009, 2011).

The first 4 questions were in multiple-choice format concerning education, specialization, place of work and position. Participants were then asked to rate their ECT knowledge in a 3-point Likert scale. The remaining 27 questions had to be answered with simple true/false choices. Five questions were related to professional and personal experiences with ECT (Q2-Q6). Eleven questions concerned knowledge (Q7, Q9, Q10, Q12, Q14, Q16, Q18-19, Q21, Q25, Q28) and 11 questions on the attitude towards ECT (Q8, Q11, Q13, Q15, Q17, Q20, Q22-24,Q26-27). Composite scores were calculated for each participant summarizing answers for the 11 questions concerning attitudes and the 11 questions concerning knowledge. Correct answers or answers suggesting a positive attitude were scored as +1 , whereas false answers or the ones suggesting a negative attitude were scored as -1 .

\section{Statistical analyses}

The data were processed using IBM SPSS Statistics, Version 21.0. Descriptive statistical data are presented as mean values with standard deviation (SD) or as a number of observations and percentages. Chi-square tests were used to compare the distribution of answers between the groups formed on the basis of workplace and profession. Two-tailed Fisher exact test was used for comparing continuous variables between the above groups. Mann-Whitney U-test was used to compare factor scores between psychiatrists and other mental health professionals and between participants who have ever worked in a psychiatric ward where they could observe ECT sessions and those who have not had such an opportunity (Question 2 in the questionnaire). The correlation between attitudes and knowledge was assessed with the Spearman rank correlation coefficient. The level of significance was set at $\mathrm{p}=0.05$.

\section{RESULTS}

One hundred and sixty-five participants (response rate: $89 \%$ ) completed the questionnaire; 35 were male and 130 were female. Their age was $41.7 \pm 9.2$ years (range: 24-62 years). Eighty-five respondents were qualified psychiatrists or psychiatric residents, and there were 63 nurses, 18 psychologists and 10 social workers. Sociodemographic characteristics is presented in Table 1.

Table 1. Socio-demographic choracteristics of the participants

\begin{tabular}{lrc}
\hline & $\mathrm{n}$ & $\%$ \\
\hline Gender & 35 & 21.2 \\
$\quad$ Male & 130 & 78.8 \\
Female & & \\
Profession & 28 & 17.0 \\
$\quad$ Trainees & 46 & 27.9 \\
Psychiatrists & 18 & 10.9 \\
$\quad$ Psychologists & 63 & 38.2 \\
$\quad$ Nurses & 10 & 6.1 \\
$\quad$ Other (social workers, paramedics) & & \\
Age & $24-62$ \\
$\quad$ Age range & $41.7 \pm 9.2$ \\
$\quad$ Mean age & & \\
Experience & 106 & 64.2 \\
$\quad$ Have worked in ECT-utilizing & & \\
$\quad$ department where observed ECT & 59 & 35.8 \\
$\quad$ Have never worked in ECT-utilizing & & \\
$\quad$ department and not witnessed ECT & & \\
Current workplace & 144 & 87.3 \\
$\quad$ Currently working in ECT-utilizing unit & 21 & 12.7 \\
$\quad$ Currently working in unit which does & & \\
$\quad$ not utilize ECT & & \\
\hline
\end{tabular}

Regarding the questions concerning knowledge about ECT, 53, 95 and 17 professionals rated themselves as having only minimal, medium and high levels of knowledge. Hundred and six of the 165 participants have worked in a hospital where ECT is offered and witnessed ECT. Only 9 participants indicated having a relative or friend who was treated with ECT. One hundred and twenty-seven participants (77\%) stated that in case if they suffered from psychotic depression, they would consent to ECT. 
The mean scores for the total attitude and knowledge subscales were $8.4 \pm 2.8$ and $4.8 \pm 4.2$, respectively. Answers to the questions concerning attitudes toward ECT revealed several false beliefs; $24.8 \%$ of the participants thought that ECT is dangerous and could be fatal, $48.5 \%$ believed that ECT should only be used as a last resort, $10.9 \%$ deemed ECT to be painful and $14.5 \%$ regarded ECT an outdated, obsolete treatment. Six percent of the participants opined that ECT is used more frequently in minor patients and $7.8 \%$ asserted that ECT causes permanent brain damage.

There were gaps in the knowledge regarding indications and contraindications for ECT and its course and effectiveness. Thirty-seven percent of the participants thought that ECT is contraindicated in myocardial infarction. According to $21 \%$ of the participants, ECT cannot be administered for patients over 65 years of age. Despite much research evidence to the contrary, $60 \%$ of the mental health professionals believed that in severe depression medication is more effective in the short term than ECT.
Items concerning attitudes/knowledge, where the rate of the false beliefs/incorrect answers was higher than $10 \%$ are presented in Table 2 .

Several significant differences in some questions appeared when comparing psychiatrists with other mental health professionals (Table 3), but the mean score for knowledge was not different between psychiatrists and trainees, and other mental health professionals $(4.7 \pm 4.1$ vs $4.8 \pm 4.3$, ns). Both groups differed, however, in the mean scores for attitude $(8.9 \pm 2.3$ vs $7.9 \pm 3.1, \mathrm{p}<0.05)$.

A comparison of the answers of participants who have ever worked in a psychiatric ward where they could observe ECT sessions and those who have not had such an opportunity are presented in Table 4. The mean scores for knowledge in the group of professionals, who have ever worked in wards offering ECT treatment vs those who have not had such an opportunity were $5.9 \pm 3.8$ vs $2.8 \pm 4.1(\mathrm{p}<0.001)$. The corresponding mean scores for attitude were $9.1 \pm 3.8$ vs $7.1 \pm 3.3(\mathrm{p}<0.001)$. Better knowledge about ECT was also related to more positive attitudes towards ECT (rs=0.366, $<<0.001)$.

Table 2. Items concerning knowledge of and attitude towards ECT, where the rate of false answers/beliefs was higher than $10 \%$

\begin{tabular}{lrr}
\hline Item & $\begin{array}{c}\text { Correct } \\
\text { answer/True }\end{array}$ & $\begin{array}{c}\text { False } \\
\text { answer/beliefs }\end{array}$ \\
\hline Q8. In Poland ECT is used more frequently than in the USA. & 148 & 17 \\
Q11. ECT was first used in the 1930s. & 60 & 105 \\
Q12. ECT is painful. & 147 & 18 \\
Q13. Convulsive therapy was devised by a Hungarian psychiatrist. & 96 & 69 \\
Q14. ECT is dangerous and may even result in death. & 98 & 41 \\
Q15. During ECT, the patient needs to be anesthetized as deeply as possible. & 85 & 67 \\
Q16. ECT may only be used as a last resort. & 99 & 80 \\
Q17. In severe depression, ECT is more effective in the short term than medication. & 66 \\
Q20. ECT is contraindicated for patients who have suffered myocardial infarction. & 141 \\
Q21. ECT is an outdated, obsolete treatment. & 130 \\
Q24. ECT can be administered in patients over 65 years of age. & 80 \\
Q26. The effectiveness of ECT is directly related to the duration of the seizure induced. & 61 \\
Q27. ECT is recommended to be used 2 or 3 times a week. & 141 \\
\hline
\end{tabular}

Table 3. Comparison of the answers of psychiatrists and trainees with other mental health care professionals. Only items with significant difference are presented

\begin{tabular}{|c|c|c|c|c|c|}
\hline \multirow[t]{2}{*}{ Item } & \multicolumn{2}{|c|}{$\begin{array}{l}\text { Psychiatrists and } \\
\text { trainees }(\mathrm{n}=85)\end{array}$} & \multicolumn{2}{|c|}{$\begin{array}{l}\text { Nurses and other } \\
\text { professionals }(n=80)\end{array}$} & \multirow[t]{2}{*}{$P$ value } \\
\hline & Yes n $(\%)$ & No $\mathrm{n}(\%)$ & Yes $\mathrm{n}(\%)$ & No $n(\%)$ & \\
\hline Q11. ECT was first used in the 1930s. & $28(32.9)$ & $57(67.1)$ & $32(40.0)$ & $48(60.0)$ & ns \\
\hline Q12. ECT is painful. & $6(7.1)$ & $79(92.9)$ & $12(15.0)$ & $68(85.0)$ & ns \\
\hline Q14. ECT is dangerous, and may even result in death. & $17(20.0)$ & $68(80.0)$ & $24(30.0)$ & $56(70.0)$ & ns \\
\hline $\begin{array}{l}\text { Q15. During ECT, the patient needs to be anesthetized } \\
\text { as deeply as possible. }\end{array}$ & $46(54.1)$ & $39(45.9)$ & $52(65.0)$ & $28(35.0)$ & ns \\
\hline Q16. ECT may only be used as a last resort. & $44(51.8)$ & $41(48.2)$ & $36(45.0)$ & $44(55.0)$ & ns \\
\hline Q19. In minority patients, ECT is used more frequently. & $1(1.2)$ & $84(98.8)$ & $9(11.3)$ & $71(88.8)$ & 0.008 \\
\hline $\begin{array}{l}\text { Q20. ECT is contraindicated for those who suffered } \\
\text { from myocardial infarction. }\end{array}$ & $37(43.5)$ & $48(56.5)$ & $24(30.0)$ & $56(70.0)$ & ns \\
\hline Q21. ECT is an outdated, obsolete treatment. & $5(5.9)$ & $80(94.1)$ & $19(23.8)$ & $61(76.3)$ & 0.002 \\
\hline
\end{tabular}


Table 4. Comparison of the answers between participants who have ever worked in a psychiatric ward where they could observe ECT sessions and those who have not had such an opportunity

\begin{tabular}{lcccrc}
\hline Questions & \multicolumn{2}{c}{$\begin{array}{c}\text { Have observed administration } \\
\text { of ECT }(\mathrm{n}=106)\end{array}$} & \multicolumn{2}{c}{$\begin{array}{c}\text { Have never observed administration } \\
\text { of ECT (n=59) }\end{array}$} & P value \\
& Yes n $(\%)$ & No n $(\%)$ & Yes n $(\%)$ & No n $(\%)$ \\
\hline Q10 & $0(0)$ & $106(100.0)$ & $5(8.5)$ & $54(91.5)$ & 0.005 \\
Q12 & $6(5.7)$ & $100(94.3)$ & $12(20.3)$ & $47(79.7)$ & 0.007 \\
Q14 & $20(18.9)$ & $86(81.1)$ & $21(35.6)$ & $38(64.4)$ & 0.024 \\
Q16 & $42(39.6)$ & $64(60.4)$ & $38(64.4)$ & $21(35.6)$ & 0.003 \\
Q17 & $78(73.6)$ & $28(26.4)$ & $21(35.6)$ & $38(64.4)$ & 0.001 \\
Q18 & $0(0)$ & $106(100.0)$ & $3(5.1)$ & $56(94.9)$ & 0.044 \\
Q20 & $27(25.5)$ & $79(74.5)$ & $34(57.6)$ & $25(42.4)$ & $<0.001$ \\
Q21 & $9(8.5)$ & $97(91.5)$ & $15(25.4)$ & $44(74.6)$ & 0.005 \\
Q22 & $103(97.2)$ & $3(2.8)$ & $50(84.7)$ & $9(15.3)$ & 0.009 \\
Q24 & $89(84.0)$ & $17(16.0)$ & $41(69.5)$ & $18(30.5)$ & 0046 \\
Q26 & $64(60.4)$ & $42(39.6)$ & $16(27.1)$ & $43(72.9)$ & $<0.001$ \\
Q27 & $98(92.5)$ & $8(7.5)$ & $8(33.3)$ & $16(66.6)$ & 0.001 \\
\hline
\end{tabular}

\section{DISCUSSION}

To the best of our knowledge, this was the first survey that evaluated the knowledge about and attitudes towards ECT, in Polish mental health professionals.

The mean knowledge score of the whole sample indicated high rate of incorrect answers. The current knowledge score was 2.5 points lower ( 4.8 vs. 7.3 ) than the one found in a similar survey in Hungary (Gazdag et al. 2004), although in the Hungarian study all participants were psychiatrists. Unexpectedly, psychiatrists in this survey scored even lower than other professionals thus the difference in the composition of the samples between the current and the Hungarian study cannot be accounted for the differing results. Nevertheless this finding calls for improving education on ECT for practicing psychiatrists in Poland by making regular ECT training part of the continuing medical education. Also, ECT should occupy a larger part of the curriculum for psychiatry trainees that should include hand-on experience.

The survey revealed several misconceptions and deficits concerning the knowledge about ECT. A number of the respondents gave incorrect answers to the basic questions related to the technique and contraindications of ECT. In line with the general lack of interest in the history of psychiatry among mental health professionals, questions targeting the history of ECT also proved to be difficult for a significant number of participants. The questions concerning the year of the first use of convulsive therapy and the identity of its inventor (Q11 and Q13) had the highest rate of incorrect answers. One of the explanations for this finding could be that in Polish language, the first descriptions and applications of electric current as a treatment in psychiatry can be found as early as in 1861 by the Polish psychiatrist Klemens Maleszewski (Nasierowski 2002, 1998). Many participants recalled that ECT was developed by Bini and Cerletti in 1938, few participants knew the name of the Hungarian psychiatrist, of Laszlo Meduna, who pioneered convulsive therapy in 1934 (Gazdag et al. 2009c).

Working in the psychiatric ward offering ECT services has reflected in both a greater knowledge about and more positive attitudes towards ECT. More favorable attitudes are positively correlated with better knowledge (Janicak 1985).

It is worth noting that psychiatrists showed more positive attitudes towards ECT than other mental health professionals. It may well be that if no better knowledge, but more extensive personal experience with the therapeutic effect of ECT might be responsible for this result. In accord with the literature (Janicak 1985, Hese et al. 2014), in this survey psychologists and social workers had more negative attitudes towards ECT compared to psychiatrists and nurses.

The rate of false answers and negative attitudes towards ECT was much higher in the group of professionals who have never observed administration of ECT. This finding confirms previous findings (Golenkov et al. 2010, Auquier et al. 1994).

Comparing the results of this survey with those of the similar Romanian and Hungarian studies conducted in 2003 and 2009, respectively several differences can be noted (Gazdag et al. 2004,2011).

The main difference is that a much higher rate of Hungarian (32\%) (Gazdag et al. 2004) and Romanian (53\%) psychiatrists (Gazdag et al. 2011) would not consent to ECT if they were severely depress in contrast to Polish mental health professionals $(23 \%)$. The rate of $23 \%$ found in this survey is still much higher than those in similar surveys in Texas (7.7\%) (Finch et al. 1999) or in France (16\%) (Auquier et al. 1994) indicating that there is still much to be done in terms of undergraduate and postgraduate education and training that would also lead to better acceptance of ECT (Royal Australian and New Zealand College of Psychiatrists Clinical Practice 
Guidelines Team for Bipolar Disorder, Australian and New Zealand clinical practice guidelines for the treatment of bipolar disorder 2004, Leiknes et al. 2012, Pranjkovic et al. 2016, Byrne et al. 2006, Lutchman et al. 2001).

In line with the results of previous studies (Gazdag et al. 2004, 2011), there was no correlation between attitudes towards ECT and psychiatric illness in the participants' family or acquaintances.

Due to methodological limitations, the results of this survey should be viewed with caution. Because of the cross-sectional design, the causality of the associations remains uncertain. The sample size was relatively small, particularly from Gostynin Hospital where ECT is not practiced (21 participants). As participation in the survey was voluntary, it is reasonable to assume that staff members with less favorable attitudes towards and poorer knowledge about ECT were more likely to refuse participation thereby biasing the results. The survey conducted in two hospitals from the same regions of the country may not reflect the situation in Poland (Hese et al. 2014); for instance, surveying academic centers might have yielded different results.

\section{CONCLUSIONS}

The main finding of this study is that mental health professionals' attitudes towards ECT is less negative compared to some other countries in the Eastern European region, but are more negative than those reported from western countries. The factor determining attitudes on ECT was working in the psychiatric ward offering such services (Pranjkovic et al. 2016). Psychiatrists showed more positive attitude towards ECT in spite of having the same level of knowledge than other mental health professionals. The findings indicate that more education and training on ECT are warranted (Pranjkovic et al. 2016, Byrne et al. 2006, Lutchman et al. 2001).

\section{Contribution of individual authors:}

Research design: Gabor Gazdag, Anna Antosik-Wójcińska \& Adam Wichniak;

Data collection: Anna Antosik-Wójcińska, Adam Wichniak \& Beata Majtczak;

Statistical analysis and data interpretation of data: Adam Wichniak \& Anna Antosik-Wójcińska;

First draft: Anna Antosik-Wójcińska, Adam Wichniak \& Gabor Gazdag;

Critical revision: Janusz Rybakowski, Paweł Gosek \& Łukasz Święcicki;

Final version of the manuscript: Anna Antosik-Wójcińska (approval of the final version) \& Gabor Gazdag (approval of the final version);

Anna Antosik-Wójcińska accepts responsibility for the integrity of the work as a whole from the design to the published article.

\section{Appendix:}

Attitude and Knowledge about Electroconvulsive Therapy (ECT) Questionnaire can be obtained from the first author.

\section{Acknowledgements: None.}

Conflict of interest: None to declare.

\section{References}

1. Auquier P, Hodgkinson M, Thirion X \& Tramoni AV: Attitude of psychiatrists to electrotherapy. Encephale 1994; 20:713-717

2. Bauer M, Pfennig A, Severus E, Whybrow PC, Angst $J$ \& Möller HJ: World Federation of Societies of Biological Psychiatry. Task Force on Unipolar Depressive Disorders: World Federation of Societies of Biological Psychiatry (WFSBP) guidelines for biological treatment of unipolar depressive disorders, part 1: update 2013 on the acute and continuation treatment of unipolar depressive disorders. World J Biol Psychiatry 2013; 14:334-85

3. Byrne P, Cassidy B \& Higgins P: Knowledge and attitudes toward electroconvulsive therapy among health care professionals and students. J ECT 2006; 22:133-8

4. Chanpattana W: ECT knowledge in psychiatrists, psychiatry residents and medical students: effect of training. $J$ Med Assoc Thai 1999; 82:819-824

5. Ellis P: Royal Australian and New Zealand College of Psychiatrists Clinical Practice Guidelines Team for Depression. Australian and New Zealand clinical practice guidelines for the treatment of depression. Aust NZJ Psychiatry 2004; 38:389-407

6. Finch JM, Sobin PB, Carmody TJ, DeWitt AP \& Shiwach RS: A survey of psychiatrists' attitudes toward electroconvulsive therapy. Psychiatr Serv 1999; 50:264-265

7. Gazdag G, Kocsis N, Tolna J \& Lipcsey A: Attitudes towards electroconvulsive therapy among Hungarian psychiatrists. J ECT 2004; 20:204-207

8. Gazdag G, Molnar E, Ungvari GS \& Iványi Z: Knowledge of and attitude toward electroconvulsive therapy. A survey of Hungarian anesthesiology residents. J ECT 2009a; 25:113-116

9. Gazdag G, Palińska D, Kłoszewska I \& Sobow T: Electroconvulsive therapy practice in Poland. J ECT 2009b; 25:34-8

10. Gazdag G, Bitter I, Ungvari G S, Baran B \& Fink M: László Meduna's pilot studies with camphor inductions of seizures: The first 11 patients. J ECT 2009c; 25:3-11

11. Gazdag G, Zsargo E, Kerti KM \& Grecu IG: Attitudes toward electroconvulsive therapy in Romanian psychiatrists. J ECT 2011; 27:55-56

12. Golenkov A, Ungvari GS \& Gazdag G: ECT practice and psychiatrists' attitudes towards ECT in the Chuvash Republic of the Russian Federation. Eur Psychiatry 2010; 25:126-128

13. Grunze H, Vieta E, Goodwin GM, Bowden C, Licht RW, Moller HJ et al: The World Federation of Societies of Biological Psychiatry (WFSBP) guidelines for the biological treatment of bipolar disorders: update 2009 on the treatment of acute mania. World J Biol Psychiatry 2009; 10:85-116 
14. Grunze H, Vieta E, Goodwin GM, Bowden C, Licht RW, Möller HJ et al: WFSBPTask Force On Treatment Guidelines For Bipolar Disorders. The World Federation of Societies of Biological Psychiatry (WFSBP) Guidelines for the Biological Treatment of Bipolar Disorders: Update 2010 on the treatment of acute bipolar depression. World J Biol Psychiatry 2010; 11:81-109

15. Hasan A, Falkai P, Wobrock T, Lieberman J, Glenthoj B, Gattaz WF et al: World Federation of Societies of Biological Psychiatry (WFSBP) Task Force on Treatment Guidelines for Schizophrenia. World Federation of Societies of Biological Psychiatry (WFSBP) Guidelines for Biological Treatment of Schizophrenia, part 1: update 2012 on the acute treatment of schizophrenia and the management of treatment resistance. World $\mathrm{J}$ Biol Psychiatry 2012; 13:318-78

16. Hasan A, Falkai P, Wobrock T, Lieberman J, Glenthøj B, Gattaz WF et al: WFSBP Task Force on Treatment Guidelines for Schizophrenia. World Federation of Societies of Biological Psychiatry (WFSBP) Guidelines for Biological Treatment of Schizophrenia. Part 3: Update 2015 Management of special circumstances: Depression, Suicidality, substance use disorders and pregnancy and lactation. World J Biol Psychiatry 2015; 16:142-70

17. Hese RT\& Zyss T: Electroconvulsive treatment in clinical practice. [in Polish] Urban \& Partner Wroclaw 2007; 5456, 63-68

18. Hese RT, Zyss $T$ \& Gorczyca P: Contemporary requirements for the electroconvulsive therapy. Letter to the Editor. Psych Pol 2014; 48:1283-1286

19. Janicak PG, Mask J, Trimakas KA \& Gibbons R: ECT: an assessment of mental health professionals' knowledge and attitude. J Clin Psychiatry 1985; 46:262-266

20. Krepela J, Hosak L, Pachlova B \& Hrdlicka M: Maintenance electroconvulsive therapy in schizophrenia. Psychiatr Danub 2019; 31:62-68
21. Lauber C, Nordt C, Falcato L \& Rössler W: Can a seizure help? The public's attitude toward electroconvulsive therapy. Psychiatry Res 2005; 134:205-209

22. Leiknes KA, Jarosh-von Schweder L \& Høie B: Contemporary use and practice of electroconvulsive therapy worldwide. Brain Behav 2012; 2:283-344

23. Lutchman RD, Stevens T, Bashir A \& Orrell M: Mental health professionals' attitudes towards and knowledge of electroconvulsive therapy. J Ment Health 2001; 10:141-150

24. Nasierowski T: The Manuscript found in Vilnius. Description of catatonic syndrome at Martin Merczys, the patient of Vilnius Department of Mad, along with the description of the attempts, taken probably for the first time in the history of psychiatry, to treat catatonia with electric current carried by the Vilnius psychiatrist Klement Maleszewski. [in Polish] Therapy 1998; 3:29-30

25. Nasierowski T: Klemens Maleszewski-pioneer of electroconvulsive therapy in Polish psychiatry. Psych Pol 2002; 36:259-269 [in Polish]

26. Palińska D, Gazdag G, Sobów T, Hese RT \& Kłoszewska I: Electroconvulsive therapy in Poland in 2005 - a nationwide questionnaire study performed in Polish psychiatric clinics Psych Pol 2008; 42:825-839 (in Polish)

27. Pranjkovic T, Degmecic D, Medic Flajsman A, Gazdag G, Ungvari GS \& Kuzman MR: Observing Electroconvulsive Therapy Changes Students' Attitudes: A Survey of Croatian Medical Students J ECT 2017; 33:26-29

28. Royal Australian and New Zealand College of Psychiatrists Clinical Practice Guidelines Team for Bipolar Disorder: Australian and New Zealand clinical practice guidelines for the treatment of bipolar disorder. Aust $N Z$ J Psychiatry 2004; 38:280-305

29. Zyss T, Rachel W, Datka W, Hese RT, Gorczyca R, Szwajca $K$ et al: Current position of electroconvulsive therapy. Part 2. Clinical Aspect. [in Polish] Przeglad lekarski 2017; 72:31-34

Correspondence:

Anna Antosik-Wójcińska, MD, PhD

Second Department of Psychiatry, Institute of Psychiatry and Neurology

Sobieskiego 9, 02-957 Warsaw, Poland

E-mail:aantosik@ipin.edu.pl 